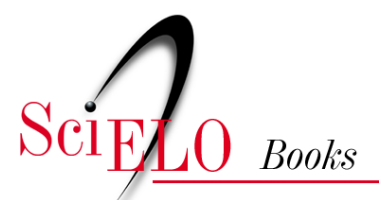

\title{
10. Breve História da Anestesia Geral
}

\author{
Joffre Marcondes de Rezende
}

REZENDE, J. M. Breve História da Anestesia Geral. In: À sombra do plátano: crônicas de história da medicina [online]. São Paulo: Editora Unifesp, 2009, pp. 103-109. História da Medicina series, vol. 2. ISBN 978-85-61673-63-5. https://doi.org/10.7476/9788561673635.0011.

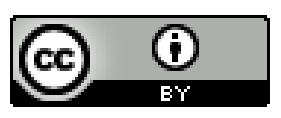

All the contents of this work, except where otherwise noted, is licensed under a Creative Commons Attribution 4.0 International license.

Todo o conteúdo deste trabalho, exceto quando houver ressalva, é publicado sob a licença Creative Commons Atribição 4.0.

Todo el contenido de esta obra, excepto donde se indique lo contrario, está bajo licencia de la licencia Creative Commons Reconocimento 4.0. 


\section{Breve História da Anestesia Geral}

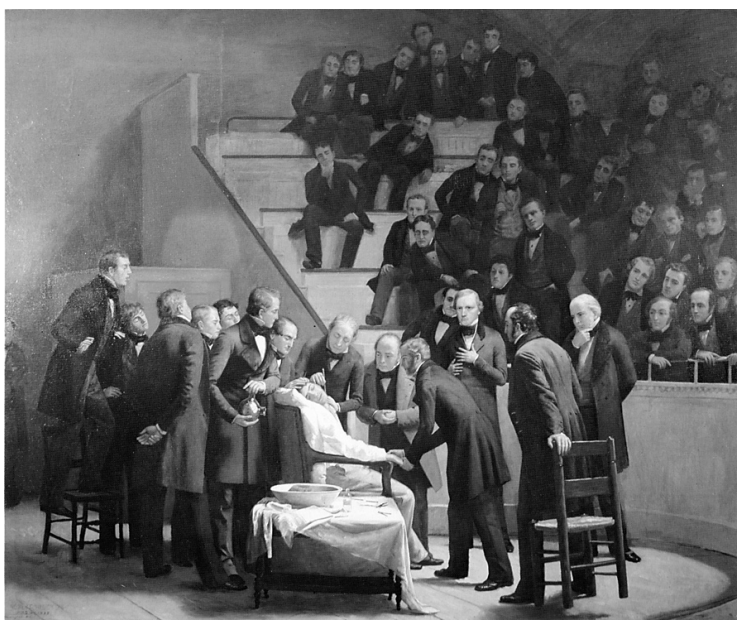

Quadro do pintor Robert Hinckley, de I 882, reproduzindo cena da operação com anestesia geral pelo éter realizada em I 6 de outubro de I 846.

$\mathrm{H}$ istoricamente, a data de I 6 de outubro de I 846 é considerada como a data em que se realizou a primeira intervenção cirúrgica com anestesia geral.

Naquele dia, às dez horas, no anfiteatro cirúrgico do Massachusetts General Hospital, em Boston, o cirurgião John Collins Warren realizou a extirpação de um tumor no pescoço de um jovem de dezessete anos, chamado Gilbert Abbot. O paciente foi anestesiado com éter pelo dentista William Thomas Green Morton, que utilizou um aparelho inalador por ele idealizado. A cena deixou de ser documentada fotograficamente, porém foi posteriormente imortalizada em um belo quadro do pintor Robert Hinckley, pintado em I 882 .

Morton, que praticara com sucesso extrações dentárias sem dor, com inalação de éter, antevira a possibilidade da cirurgia sem dor e obtivera autorização para uma demonstração naquele hospital.

Morton não revelara a natureza química da substância que utilizava, dando-lhe o nome de letheon (do grego lethe, rio do esquecimento). Pressionado 
pela Associação Médica de Boston para que novas intervenções pudessem ser realizadas sem dor, teve de revelar a composição do letheon, que era apenas éter sulfúrico puro (Rutkov, I998, pp. 89-90).

A insensibilidade total durante o ato cirúrgico, até então, era considerada uma utopia nos meios acadêmicos.

À exceção da China, onde se usava a milenar acupuntura, os recursos utilizados para amenizar a dor no ato cirúrgico consistiam de extratos de plantas dotadas de ação sedativa e analgésica, além da hipnose e bebidas alcoólicas, o que não dispensava, evidentemente, a contenção do paciente.

$\mathrm{Na}$ Idade Média empregava-se um método originário da escola de Alexandria, cuja fórmula foi encontrada no mosteiro de Monte Casino. Trata-se da esponja soporífera, que se preparava com os seguintes componentes: ópio, suco de amoras amargas, suco de eufórbia, suco de meimendro, suco de mandrágora, suco de hera, sementes de bardana, sementes de alface e sementes de cicuta - uma onça de cada $(28,7 \mathrm{~g})$. Modo de preparar e de usar: misturar bem, colocar em um recipiente de cobre com uma esponja, ferver até a evaporação total. Para usar, mergulhar a esponja em água quente por uma hora; a seguir colocá-la sob as narinas do paciente até que ele durma. Para despertar o paciente usar outra esponja embebida em vinagre (Major, 1954, p. 272).

O primeiro passo para a anestesia geral foi dado por Joseph Priestley, ao descobrir o óxido nitroso $\left(\mathrm{N}_{2} \mathrm{O}\right)$ em $\mathrm{I} 773$.

Coube a Humphry Davy, um aprendiz de farmácia, na pequena cidade de Penzance, na Inglaterra, em I796, experimentar os efeitos da inalação do óxido nitroso. Ele verificou que o gás produzia uma sensação agradável, acompanhada de um desejo incontido de rir (por isso o nome de gás hilariante). Certa noite estava com dor de dente e, ao inalar o gás, notou que a dor desaparecera por completo. Deduziu que, se o óxido nitroso suprimia a dor, poderia ser empregado no tratamento de outros tipos de dor. Em um de seus escritos, intitulado "Vapores Medicinais", sugeriu o emprego do óxido nitroso em cirurgia: "Já que o gás hilariante parece possuir a propriedade de acalmar as dores físicas, seria recomendável empregá-lo contra as dores cirúrgicas". A medicina oficial não tomou conhecimento da sugestão.

Henry Hill Hickman, médico e cirurgião inglês, experimentara em animais a ação do gás carbônico, tendo verificado que, sob a ação deste gás, 
podia realizar pequenas operações nos animais, sem que estes demonstrassem o menor sinal de dor. Tentou, sem êxito, obter autorização da Royal Society e da Associação Médica de Londres para repetir suas experiências em seres humanos. Sua petição foi recebida com frieza, a autorização negada e ele foi considerado um visionário.

Como última tentativa, escreveu ao rei da França, Carlos x, pedindo-lhe para submeter o seu projeto à consideração da Academia de Paris. Em sessão de 28 de setembro de I 828 , convocada especialmente para esse fim, a Academia deu seu parecer contrário, com um único voto a favor, do cirurgião Dominique Jean Larrey, que servira ao exército de Napoleão e conhecia o horror dos ferimentos de guerra e das amputações. Velpeau, um dos mais eminentes cirurgiões da França, havia declarado que considerava uma quimera a obtenção da insensibilidade dolorosa durante o ato cirúrgico.

Desiludido, Hickman faleceu dois anos depois, com trinta anos incompletos, sem ver realizado o seu sonho da cirurgia sem dor.

Michael Faraday (I79I-I 867), físico inglês, estudando a liquefação dos gases e os líquidos voláteis, descobrira que os vapores de éter possuíam efeitos inebriantes semelhantes aos do óxido nitroso. Em uma nota publicada no Journal of Art and Sciences chamou a atenção para o fato da inalação de éter produzir insensibilidade total. Novamente, essa descoberta foi ignorada pelos meios médicos.

Nos Estados Unidos, os efeitos inebriantes do óxido nitroso e do éter tornaram-se conhecidos e eram frequentes os espetáculos públicos de inalação de gás hilariante, assim como reuniões reservadas de inalação de éter, conhecidas como ether parties ou ether frolics.

Foi em um desses espetáculos de inalação de gás hilariante que Horace Wells, dentista na cidade de Hartford, tomou conhecimento da propriedade do óxido nitroso de causar insensibilidade. Teve, então, a ideia de utilizá-lo em extrações dentárias. Fez uma experiência em si mesmo, solicitando a um seu colega que lhe extraísse um dente após inalação do $\mathrm{N}_{2} \mathrm{O}$. Não somente não sentiu dor, como experimentou uma sensação de euforia e bem-estar. Entusiasmado, dirigiu-se à Boston, onde conseguiu permissão para fazer uma demonstração perante professores e estudantes da Faculdade de Medicina de Harvard. Um estudante se ofereceu como cobaia e a demonstração foi 
um fracasso. O estudante gritou de dor e Wells foi posto para fora como charlatão e impostor.

Ao fazer nova tentativa em sua cidade, administrou quantidade excessiva de gás e o paciente teve parada respiratória e por pouco não morreu. Desanimado, abandonou suas experiências e a profissão de dentista.

Outro dentista, de Boston, William Thomas Green Morton, perseverou no propósito de obter extrações dentárias sem dor e sem colocar em risco a vida do paciente. Substituiu o óxido nitroso por éter, após consultar seu ex-professor de química, Charles Thomas Jackson, que lhe recomendou usar somente éter retificado e indicou-lhe o local onde poderia obtê-lo. Os resultados foram surpreendentes e muito superiores aos obtidos com o $\mathrm{N}_{2} \mathrm{O}$. Morton antevira a possibilidade da cirurgia sem dor e obteve permissão para uma demonstração no Massachusetts General Hospital (Bobbio, I969, pp. 66-84; Fülop-Miller, I95 I, pp. 99-I74).

Assim chegamos ao dia I 6 de outubro de I 846 , que mudou o destino da cirurgia. Warren proferiu as seguintes palavras: "Daqui a muitos séculos, os estudantes virão a este hospital para conhecer o local onde se demonstrou pela primeira vez a mais gloriosa descoberta da ciência" (Fülop-Miller, $o p$. cit., p. I 58 ).

$\mathrm{Na}$ realidade, esta não era a primeira intervenção cirúrgica realizada com anestesia geral pelo éter. Na pequena cidade de Jefferson, no estado da Geórgia, nos Estados Unidos, em I84I, um jovem médico de nome Crawford Williamson Long tinha o hábito de realizar sessões de ether frolics em sua casa. Long participou de várias sessões e teve sua atenção despertada para a insensibilidade que se produzia durante os efeitos do éter, pois, por mais de uma vez, havia se machucado sem nada sentir. Teve, então, a ideia de utilizar o éter em pequenas intervenções cirúrgicas. $O$ primeiro paciente a ser operado sob a ação do éter foi um amigo de nome Venable.

$\mathrm{Na}$ presença de várias pessoas Long extirpou dois pequenos tumores na nuca do paciente sem que ele nada sentisse. A insensibilidade poderia ser atribuída à hipnose e não ao éter e para obter a prova decisiva, Long aproveitou-se de uma oportunidade ímpar. O filho de um escravo havia queimado a mão e necessitava amputar dois dedos. Long amputou o primeiro deles sob a ação do éter e o segundo depois de cessado o efeito do éter. $\mathrm{O}$ rapaz acusou dor somente na segunda amputação. 
Long chegou a operar oito casos com anestesia pelo éter, porém acreditava que o método não servisse para grandes intervenções a não ser que o paciente inalasse o éter o tempo todo, o que seria arriscado. Circularam rumores na cidade de que o médico estava pondo em risco a vida dos pacientes e certo dia uma comissão constituída das autoridades locais foi ao seu consultório pedir para que ele renunciasse a essas práticas audaciosas, pois, se um doente morresse ele poderia ser linchado em consequência da revolta da população, costume que era frequente na época. Long abandonou o uso do éter e suas experiências pioneiras só se tornaram conhecidas anos depois (Idem, p. Iо8; Lee e Atkinson, I976, pp. 4-5).

Com o sucesso de Morton, Jackson, que gozava de prestígio internacional, reivindicou para si, nos países europeus, a prioridade da descoberta, acusando Morton de desonestidade.

Wells, desgostoso e amargurado com o seu fracasso, cometeu desatinos, foi preso e suicidou-se na prisão aos 33 anos de idade.

Morton, empobrecido, desacreditado por Jackson, faleceu subitamente em uma via pública aos 49 anos de idade. Com sua morte, houve um despertar da consciência norte-americana a seu favor e no local de sua sepultura foi erigido um monumento com o seguinte epitáfio: "Aqui jaz W. T. G. Morton, o descobridor e inventor da anestesia. Antes dele, a cirurgia era sinônimo de agonia. Por ele foram vencidas e aniquiladas as dores do bisturi. Depois dele a ciência é senhora da dor. Erigido pelos cidadãos reconhecidos de Boston" (Fülop-Miller, op. cit., p. 286).

Jackson, ao tomar conhecimento deste epitáfio, sentiu-se finalmente derrotado, tornou-se alcoólatra e terminou seus dias em um hospício, onde morreu em i 880, aos 75 anos de idade.

Long viveu o resto de sua vida arrependido por não ter divulgado sua descoberta, realizada em I 842, portanto, quatro anos antes de Morton, e faleceu subitamente aos 63 anos de idade.

Como escreveu Fülop-Miller, dir-se-ia que uma estranha maldição pairava sobre todos os que consagraram sua vida e sua obra a lutar contra a dor.

Embora Crawford Long tenha sido o primeiro médico a utilizar-se da anestesia geral pelo éter, o mérito e a glória da sua revelação para o mundo cabe, inegavelmente, a William Thomas Green Morton. 
Nos anos seguintes à sua descoberta, foram introduzidos novos agentes anestésicos. Ao óxido nitroso e ao éter seguiu-se o clorofórmio, utilizado pela primeira vez em I 847 , no trabalho de parto, pelo médico inglês James Simpson. Em I930 foi introduzido o ciclopropano e em I956, o halotano (Lee, op. cit., pp. 23-24).

Paralelamente à anestesia geral por inalação, desenvolveram-se outros métodos de se obter a analgesia, como a anestesia local, venosa, raquianestesia etc.

O termo anestesia (do grego an, privado de + aísthesis, sensação) foi sugerido pelo médico e poeta norte-americano Oliver Wendel Holmes. A palavra, entretanto, já existia na língua grega, tendo sido empregada no sentido de insensibilidade dolorosa pela primeira vez por Dioscórides, no século I d.C.

Em I902, Seifert criou o termo anestesiologia, que define, atualmente, uma das mais importantes especialidades médicas (Villegas, s.d.).

A anestesia geral chegou ao Brasil em I 847. Segundo informa Lycurgo Santos Filho, em sua História Geral da Medicina Brasileira, a primeira anestesia geral pelo éter foi praticada no Hospital Militar do Rio de Janeiro pelo médico Roberto Jorge Haddock Lobo, em 25 de maio de I 847. Uma semana após foi utilizada por Domingos Marinho de Azevedo Americano em dois soldados, tendo sido anestesista o médico Leslie Castro, recém-chegado da Europa e que trazia consigo o anestésico e o aparelho de "eterização". Um dos soldados foi operado com sucesso, sem dor, de osteomielite fistulizada da mastoide; o outro era acoólatra e a anestesia não produziu insensibilidade.

O éter foi logo substituído pelo clorofórmio que havia sido introduzido como anestésico na Inglaterra por James Simpson, em I847. A primeira anestesia geral com o clorofórmio foi empregada pelo prof. Manuel Feliciano Pereira de Carvalho, na Santa Casa de Misericórdia do Rio de Janeiro, em i 8 de fevereiro de I 848, e noticiada pelo Jornal do Commercio em 22 do mesmo mês, com base em anotações fornecidas pelo prof. Luís da Cunha Feijó, que assistira à operação, uma amputação da coxa em um rapaz de quinze anos, por "tumor branco do joelho" (tuberculose) (Santos Filho, r991, pp. 337-342).

A partir de então o uso do clorofórmio se generalizou, suplantando o éter, até que novos agentes anestésicos foram descobertos e introduzidos na prática médica. 


\section{Referências Bibliográficas}

Bовbio, A. História Sinóptica da Anestesia. São Paulo, Nobel, I969.

Fülop-Miller, R. O Triunfo sobre a Dor. História da Anestesia. $2^{\mathrm{a}}$ ed., Rio de Janeiro, José Olympio, I95I.

Grant, J. Hackh’s Chemical Dictionary. $4^{\underline{a}}$ ed., Nova York, McGraw-Hill Book Co., I972.

Lee, J. A. \& Atrinson, R. S. Manual de Anestesiologia. Rio de Janeiro, Livraria Atheneu, I976.

Major, R. H. A History of Medicine. Oxford, Blackwell Scientific Publications, I954.

Rutkov, I. M. American Surgery. An Illustrated History. Philadelphia, Lippincott-Raven, I998.

Santos Filho, L. História Geral da Medicina Brasileira. São Paulo, Edusp/Hucitec, I991.

Villegas, Z. C. "Historia de la Anestesia: Louis Ombredanne”. Disponível em http:// www.inmedsuc. 8 m.com/I3 I/historia2.htm, acesso em 26 ago. 2009. 
